\title{
A Survey on the Status and the Importance of Initial History Taking in Dental Clinics in S Area
}

\author{
Do-Seon Lim, Im-Hee Jung, Ae-Jung Im, and Hee-Jung Lim ${ }^{\dagger}$ \\ Department of Dental Hygiene, College of Health Science, Eulji University, Seongnam 13135, Korea
}

\begin{abstract}
Background: A comprehensive history taking at the first visit could be an important start of treatment. This study investigated the current status of the initial history taking for dental patients in $\mathrm{S}$ area, and the implementation and importance of the initial history taking process. Based on this, we intend to provide basic data for the development of organized and standardized questionnaires in dental clinics.

Methods: In April 2019, 303 dental clinics in S area were targeted and special dental clinics (orthodontics, children, and disabled) were excluded. The questionnaire consisted of 29 items, including general characteristics, systemic disease history, dental history, oral health behaviors, and the data were obtained through self-administered questionnaire.

Results: Initial history taking was mostly implemented using oral and questionnaire at the time of the first visit. Systemic disease history, dental history, and oral health behaviors differed in the work experience of the dental clinic staff. As a result of analyzing the importance according to implementation, there were significant differences in all questions except drug-related items. The importance of the questionnaire was highly recognized, but the reason it was not actually implemented was because of existing the questionnaire in the clinic and lack of time.

Conclusion: Considering that the initial history taking implementation rate showed low, it is necessary to develop standardize a practical questionnaire and interview skills for dental clinics in the future. In addition, training programs should be provided to dental staff that can recognize the importance of initial history taking questionnaires and contribute to active implementation.
\end{abstract}

Key Words: Implementation, Importance, Initial history taking

\section{Introduction}

Owing to recent advances of medicine and consequent increase of average life expectancy, South Korea became an aged society in 2017 with its older adult population exceeding $14 \%$, and the prevalence of chronic diseases among adults aged 30 years or older is also on the rise ${ }^{1,2)}$. Moreover, $83.5 \%$ of the entire older adult population is currently taking an average of 3.9 prescribed medications ${ }^{3)}$. For this reason, the numbers of elderly patients, patients with chronic diseases, and individuals taking medications are anticipated to increase further, necessitating more accurate initial history taking related to systemic diseases.

Park ${ }^{4)}$ observed that there were several medical malpractice cases that occurred as a result of inadequate history taking related to systemic diseases in Japan. In Korea, one patient developed cerebral infarction during a dental procedure that had been performed without measuring blood pressure before the procedure ${ }^{5)}$. In addition, there have been cases of osteonecrosis of the jaw in patients with osteoporosis who have taken oral bisphosphonate or given bisphosphonate injections for a prolonged period, again highlighting the importance of detailed history taking to identify any relevant disease history ${ }^{6,7)}$. Therefore, accurate initial history taking before dental care is crucial not only in terms of physical but also mental factors to prevent medical malpractices. Hence, understanding the level of patients' anxiety, depression, and fear through 
initial history taking would help alleviate their anxiety and fear, which would contribute to pain control and effective dental care.

The Enforcement Decree of the Medical Service Technologists, etc. Act stipulates that dental hygienists have the mission to improve patients' oral health by motivating behavioral changes through "removal of plaques, fluoride application to prevent dental caries, and other tasks pertinent to the prevention of dental and oral diseases and oral hygiene" under the supervision of a dentist $^{8)}$. Thus, initial history taking should include current oral symptoms but also patient's oral health behaviors in order to contribute to preventing oral diseases and promoting oral health.

The study with a focus on BRONJ (bisphosphonate related osteonecrosis of the jaw) of osteoporosis patients by $\mathrm{Heo}^{9)}$ is practically the only study regarding dental history taking in Korea, and thus it is important to investigate the current status of dental initial history taking and the importance of the items asked on the questionnaire. Through such examination, we aim to promote effective and cooperative dental care, prevent medical malpractices, and ultimately present foundational data for developing standardized patient questionnaires.

\section{Materials and Methods}

\section{Participants}

An in-person self-report questionnaire was administered to dental hygienists who are in charge of initial history taking in 428 dental hospitals and clinics, with the exception of specialized clinics (e.g., orthodontics, pediatric, and clinics for the disabled) in $\mathrm{S}$ region of Gyeonggi Province from April 1 to April 30, 2019. The participants were informed of the purpose of the study and confidentiality, and after excluding questionnaires with no consents or careless responses, a total of 303 questionnaires were included in the final analysis.

\section{Instrument}

The instrument for this study was developed based on the patient questionnaire in the clinical training chart used in Eulji University and the history taking in dental clinics to prevent $\mathrm{BRONJ}^{9)}$. The questionnaire consisted of 29 items, with 4 items for general characteristics, 9 items for systemic disease history, 7 items for dental history, 8 items for oral health behaviors, and 1 item asking about the reason for noncompliance despite perceived importance.

\section{Analysis}

The collected data were analyzed using the SPSS Statistical Package for the Science Version 23 software (IBM Corp., Armonk, NY, USA) at a significance of 0.05 . Participants' general characteristics and history taking items (systemic disease history, dental history, and oral health behaviors), compliance, perceived importance, and differences were analyzed with frequency analysis, independent t-test, and one-way ANOVA, followed by the Scheffe test as the post-hoc test.

\section{Results}

\section{Mean compliance rate with each section in history taking questionnaire}

The mean compliance rate with each section in history taking questionnaire was 6.55 out of 9 items in systemic disease history, 4.53 out of 7 items in dental history, and 5.11 out of 8 items in oral health behaviors (Table 1).

\section{Mean compliance rate with each section according general characteristics}

Table 2 shows the mean compliance rate with systemic disease history, dental history, and oral health behavior sections of the history taking questionnaire. For items about systemic diseases, participants used a questionnaire most frequently, and there was a significant difference $(p=0.001)$. Compliance with items about dental history was the highest among participants with a career of less

Table 1. Mean Compliance Rate with Each Section

\begin{tabular}{lcc}
\hline \multicolumn{1}{c}{ Variable } & $\begin{array}{c}\text { Total } \\
\text { number } \\
\text { of items }\end{array}$ & $\begin{array}{c}\text { Mean number of items } \\
\text { used (mean } \pm \text { standard } \\
\text { deviation) }\end{array}$ \\
\hline Systemic disease history & 9 & $6.55 \pm 1.99$ \\
Dental history & 7 & $4.53 \pm 1.76$ \\
Oral health behaviors & 8 & $5.11 \pm 2.11$ \\
\hline
\end{tabular}


Table 2. Number of Items Used for Systemic Disease History, Dental History, and Oral Health Behaviors according to General Characteristics $(n=303)$

\begin{tabular}{|c|c|c|c|c|c|c|c|}
\hline \multirow[b]{2}{*}{ Variable } & \multirow[b]{2}{*}{$\mathrm{n}$} & \multicolumn{2}{|c|}{ Systemic disease history } & \multicolumn{2}{|c|}{ Dental history } & \multicolumn{2}{|c|}{ Oral health behaviors } \\
\hline & & $\begin{array}{l}\text { Mean } \pm \text { standard } \\
\text { deviation }\end{array}$ & p-value & $\begin{array}{c}\text { Mean } \pm \text { standard } \\
\text { deviation }\end{array}$ & p-value & $\begin{array}{l}\text { Mean } \pm \text { standard } \\
\text { deviation }\end{array}$ & $\mathrm{p}$-value \\
\hline Sex & & & 0.549 & & 0.110 & & 0.119 \\
\hline Male & 11 & $6.91 \pm 2.21$ & & $5.36 \pm 1.74$ & & $6.09 \pm 1.57$ & \\
\hline Female & 292 & $6.54 \pm 1.99$ & & $4.50 \pm 1.75$ & & $5.08 \pm 2.12$ & \\
\hline Length of career $(y)$ & & & 0.063 & & 0.026 & & 0.014 \\
\hline$<5$ & 39 & $7.15 \pm 1.84$ & & $5.26 \pm 1.72^{\mathrm{b}}$ & & $6.10 \pm 1.09^{\mathrm{b}}$ & \\
\hline $5 \sim 10$ & 94 & $6.17 \pm 1.89$ & & $4.39 \pm 1.74^{\mathrm{a}}$ & & $4.86 \pm 2.06^{\mathrm{a}}$ & \\
\hline $10 \sim 15$ & 80 & $6.60 \pm 2.06$ & & $4.26 \pm 1.77^{\mathrm{a}}$ & & $4.93 \pm 2.10^{\mathrm{a}}$ & \\
\hline$\geq 16$ & 90 & $6.66 \pm 2.05$ & & $4.60 \pm 1.71^{\mathrm{ab}}$ & & $5.11 \pm 2.18^{\mathrm{ab}}$ & \\
\hline Type of dental facility & & & 0.779 & & 0.446 & & 0.124 \\
\hline General hospital $\cdot$ dental hospital & 8 & $6.75 \pm 2.37$ & & $5.00 \pm 2.13$ & & $6.25 \pm 1.98$ & \\
\hline Dental hospital & 295 & $6.55 \pm 1.98$ & & $4.52 \pm 1.75$ & & $5.08 \pm 2.11$ & \\
\hline Number of patients & & & 0.127 & & 0.640 & & 0.920 \\
\hline$\geq 15$ & 93 & $6.38 \pm 2.13$ & & $4.51 \pm 1.81$ & & $5.01 \pm 2.43$ & \\
\hline $16 \sim 20$ & 83 & $6.41 \pm 2.01$ & & $4.59 \pm 1.84$ & & $5.10 \pm 2.09$ & \\
\hline $21 \sim 30$ & 87 & $6.57 \pm 1.78$ & & $4.38 \pm 1.66$ & & $5.16 \pm 1.87$ & \\
\hline$>30$ & 40 & $7.23 \pm 1.99$ & & $4.80 \pm 1.69$ & & $5.28 \pm 1.90$ & \\
\hline Type of history taking & & & 0.001 & & 0.144 & & 0.015 \\
\hline Verbal & 71 & $5.82 \pm 2.14^{\mathrm{a}}$ & & $4.20 \pm 1.84$ & & $4.63 \pm 2.33^{\mathrm{a}}$ & \\
\hline Questionnaire & 39 & $7.08 \pm 1.91$ & & $4.82 \pm 2.05$ & & $5.85 \pm 2.13^{\mathrm{b}}$ & \\
\hline Verbal and questionnaire & 193 & $6.72 \pm 1.89^{c}$ & & $4.60 \pm 1.65$ & & $5.14 \pm 1.99^{\mathrm{c}}$ & \\
\hline Timing of history taking & & & 0.293 & & 0.090 & & 0.404 \\
\hline At the new patient visit & 286 & $6.58 \pm 1.99$ & & $4.49 \pm 1.75$ & & $5.09 \pm 2.10$ & \\
\hline As needed & 17 & $6.06 \pm 2.01$ & & $5.24 \pm 1.71$ & & $5.53 \pm 2.32$ & \\
\hline
\end{tabular}

Post hoc test was conducted from Scheffe test.

p-value by t-test or one-way ANOVA.

than five years and lowest among participants with a career of $10 \sim 15$ years, with a significant difference between the two groups $(p<0.05)$. Compliance with items about oral health behaviors was the highest among participants with a career of less than five years, and a questionnaire was most commonly used, with a significant difference $(\mathrm{p}<0.05)$.

\section{Importance according to compliance with specific categories about systemic disease}

Regarding the importance according to the compliance with specific categories about systemic disease, the results were significant for all items with the exception of items about medications $(p<0.05)$ (Table 3$)$. In particular, items about systemic diseases were perceived to be most important during history taking, followed by items about delayed hemostasis during hemorrhage and items about infectious diseases. On the other hand, items about surgery and hospitalization were perceived to be least important during history taking.

\section{Compliance rate for each category of systemic disease}

The compliance rate within the systemic disease section was the highest for diabetes mellitus and hypertension (96.7\% each), followed by heart disease (90.8\%), hepatitis (86.8\%), and tuberculosis (78.5\%). The compliance rate was the lowest for sexually transmitted disease (27.7\%) and mental disorders (37.0\%) (Table 4).

\section{Importance according to compliance with specific categories about dental history}

Regarding the importance according to the compliance with specific categories about dental history, the results 
Table 3. Importance according to the Use of Items in Systemic Disease History Section $(n=303)$

\begin{tabular}{|c|c|c|c|c|}
\hline \multirow[b]{2}{*}{ Item } & & \multirow[b]{2}{*}{$\mathrm{n}$} & \multicolumn{2}{|c|}{ Importance } \\
\hline & & & $\begin{array}{l}\text { Mean } \pm \text { standard } \\
\text { deviation }\end{array}$ & p-value \\
\hline \multirow{2}{*}{$\begin{array}{l}\text { Check patient's vital signs (ex. blood pressure, body temperature, pulse, } \\
\text { breathing rate) }\end{array}$} & Yes & 85 & $4.37 \pm 0.73$ & $<0.001$ \\
\hline & No & 218 & $3.52 \pm 0.79$ & \\
\hline \multirow{2}{*}{$\begin{array}{l}\text { Items about systemic disease (ex. presence of diseases, treatment, time of } \\
\text { diagnosis) }\end{array}$} & Yes & 296 & $4.69 \pm 0.58$ & $<0.001$ \\
\hline & No & 7 & $3.87 \pm 0.69$ & \\
\hline \multirow{2}{*}{$\begin{array}{l}\text { Items about medications (ex. use of medications, type of medication, duration } \\
\text { of medication use, adverse reactions) }\end{array}$} & Yes & 296 & $4.65 \pm 0.56$ & 0.304 \\
\hline & No & 7 & $4.42 \pm 0.53$ & \\
\hline \multirow[t]{2}{*}{ Items about radiation therapy (ex. treatment, location, duration of treatment) } & Yes & 171 & $4.38 \pm 0.72$ & $<0.001$ \\
\hline & No & 132 & $2.80 \pm 0.91$ & \\
\hline \multirow{2}{*}{$\begin{array}{l}\text { Items about surgery and hospitalization (ex. surgery/hospitalization, time, } \\
\text { location, length of hospital stay) }\end{array}$} & Yes & 208 & $4.12 \pm 0.80$ & $<0.001$ \\
\hline & No & 95 & $2.83 \pm 1.04$ & \\
\hline \multirow[t]{2}{*}{ Items about delayed hemostasis during hemorrhage } & Yes & 277 & $4.59 \pm 0.62$ & $<0.001$ \\
\hline & No & 26 & $3.42 \pm 1.06$ & \\
\hline \multirow[t]{2}{*}{ Items about family history } & Yes & 84 & $4.20 \pm 0.94$ & $<0.001$ \\
\hline & No & 219 & $2.84 \pm 0.95$ & \\
\hline \multirow{2}{*}{$\begin{array}{l}\text { Items about respiratory diseases (ex. presence of respiratory diseases, time, } \\
\text { whether disease is active) }\end{array}$} & Yes & 174 & $4.33 \pm 0.70$ & $<0.001$ \\
\hline & No & 129 & $3.10 \pm 0.89$ & \\
\hline \multirow{2}{*}{$\begin{array}{l}\text { Items about infectious diseases (ex. presence of infectious diseases, time, } \\
\text { whether cured or not }\end{array}$} & Yes & 267 & $4.56 \pm 0.67$ & $<0.001$ \\
\hline & No & 36 & $3.36 \pm 0.99$ & \\
\hline
\end{tabular}

p-value by t-test.

Table 4. Compliance Rate with Each Category of Systemic Diseases

\begin{tabular}{|c|c|c|c|c|c|}
\hline \multicolumn{2}{|l|}{ Name of disease } & \multirow{2}{*}{$\begin{array}{c}\text { Compliance rate }(\%) \\
42.6\end{array}$} & \multicolumn{2}{|c|}{ Name of disease } & \multirow{2}{*}{$\begin{array}{c}\text { Compliance rate }(\%) \\
96.7\end{array}$} \\
\hline Thyroid disease & Yes & & Diabetes mellitus & Yes & \\
\hline & No & 57.4 & & No & 3.3 \\
\hline \multirow[t]{2}{*}{ Hepatitis } & Yes & 86.8 & Hypertension & Yes & 96.7 \\
\hline & No & 13.2 & & No & 3.3 \\
\hline \multirow[t]{2}{*}{ HIV } & Yes & 37.3 & Heart disease & Yes & 90.8 \\
\hline & No & 62.7 & & No & 9.2 \\
\hline \multirow[t]{2}{*}{ Sexually transmitted disease } & Yes & 27.7 & Tuberculosis & Yes & 78.5 \\
\hline & No & 72.3 & & No & 21.5 \\
\hline \multirow[t]{2}{*}{ Mental disorder } & Yes & 37.0 & Pneumonia & Yes & 50.5 \\
\hline & No & 63.0 & & No & 49.5 \\
\hline \multirow[t]{2}{*}{ Cancer } & Yes & 41.6 & Rheumatism & Yes & 37.3 \\
\hline & No & 58.4 & & No & 62.7 \\
\hline \multirow[t]{2}{*}{ Pregnancy } & Yes & 80.5 & Osteoporosis & Yes & 84.5 \\
\hline & No & 19.5 & & No & 15.5 \\
\hline \multirow[t]{2}{*}{ Kidney disease } & Yes & 52.1 & Other & Yes & 13.5 \\
\hline & No & 47.9 & & No & 86.5 \\
\hline
\end{tabular}

were significant for all items $(\mathrm{p}<0.05)$ (Table 5). The participants perceived notable findings during dental treatment (e.g., difficulty of anesthesia, allergic to dental materials) to be the most important. On the other hand, the participants perceived patients' perceived oral health status to be less important.

\section{Importance according to compliance with specific categories about oral health behaviors}

Regarding the importance according to the compliance with specific categories about oral health behaviors, the results were significant for all items $(\mathrm{p}<0.05)$ (Table 6). 
Table 5. Importance according to Compliance with Each Category of Dental History $(n=303)$

\begin{tabular}{|c|c|c|c|c|}
\hline \multirow[b]{2}{*}{ Item } & & \multirow[b]{2}{*}{$\mathrm{n}$} & \multicolumn{2}{|c|}{ Importance } \\
\hline & & & $\begin{array}{l}\text { Mean } \pm \text { standard } \\
\text { deviation }\end{array}$ & p-value \\
\hline \multirow{2}{*}{$\begin{array}{l}\text { Items about past dental treatment (ex. dental plaque removal, tooth } \\
\text { extraction, orthodontic treatment, implant) }\end{array}$} & Yes & 254 & $4.19 \pm 0.71$ & $<0.001$ \\
\hline & No & 49 & $3.20 \pm 0.76$ & \\
\hline \multirow{2}{*}{$\begin{array}{l}\text { Items about current oral symptoms (ex. dental caries, toothache, dry } \\
\text { mouth, temporomandibular pain, bad breath ) }\end{array}$} & Yes & 288 & $4.43 \pm 0.68$ & 0.012 \\
\hline & No & 15 & $3.60 \pm 1.12$ & \\
\hline \multirow{2}{*}{$\begin{array}{l}\text { Items about notable findings during dental treatment (ex. difficulty of } \\
\text { anesthesia, allergic to dental materials) }\end{array}$} & Yes & 266 & $4.50 \pm 0.65$ & $<0.001$ \\
\hline & No & 37 & $2.94 \pm 0.81$ & \\
\hline \multirow{2}{*}{$\begin{array}{l}\text { Items about radiotherapy for head and neck (ex. history of treatment, time } \\
\text { of treatment) }\end{array}$} & Yes & 99 & $4.19 \pm 0.77$ & $<0.001$ \\
\hline & No & 204 & $3.01 \pm 0.84$ & \\
\hline \multirow[t]{2}{*}{ Items about fear of dental care (ex. presence of fear, trigger) } & Yes & 185 & $4.21 \pm 0.74$ & $<0.001$ \\
\hline & No & 118 & $3.09 \pm 0.84$ & \\
\hline \multirow[t]{2}{*}{ Items about perceived oral health status (ex. good $\Rightarrow$ poor ) } & Yes & 134 & $3.98 \pm 0.80$ & $<0.001$ \\
\hline & No & 169 & $3.07 \pm 0.83$ & \\
\hline \multirow{2}{*}{$\begin{array}{l}\text { Items about current bad oral habits (ex. presence of bad oral habits, } \\
\text { factors) }\end{array}$} & Yes & 150 & $4.05 \pm 0.80$ & $<0.001$ \\
\hline & No & 153 & $3.09 \pm 0.77$ & \\
\hline
\end{tabular}

p-value by t-test.

Table 6. Importance according to Compliance with Each Category of Oral Health Behaviors $(n=303)$

\begin{tabular}{|c|c|c|c|c|}
\hline \multirow[b]{2}{*}{ Item } & & \multirow[b]{2}{*}{$\mathrm{n}$} & \multicolumn{2}{|c|}{ Importance } \\
\hline & & & $\begin{array}{l}\text { Mean } \pm \text { standard } \\
\text { deviation }\end{array}$ & p-value \\
\hline \multirow{2}{*}{$\begin{array}{l}\text { Items about type of dental visit (ex. regular visit, visit only when sick or } \\
\text { in presence of a problem) }\end{array}$} & Yes & 221 & $4.24 \pm 0.76$ & $<0.001$ \\
\hline & No & 82 & $3.15 \pm 0.89$ & \\
\hline \multirow[t]{2}{*}{ Items about scaling (ex. history, most recent scaling) } & Yes & 272 & $4.37 \pm 0.69$ & $<0.001$ \\
\hline & No & 31 & $3.38 \pm 0.76$ & \\
\hline \multirow[t]{2}{*}{ Items about oral health education (ex. history, content of education) } & Yes & 157 & $4.19 \pm 0.82$ & $<0.001$ \\
\hline & No & 146 & $3.09 \pm 0.85$ & \\
\hline \multirow{2}{*}{$\begin{array}{l}\text { Items about cariogenic foods (ex. consumption of such foods, types of } \\
\text { foods normally consumed, frequency of food consumption) }\end{array}$} & Yes & 83 & $4.06 \pm 0.83$ & $<0.001$ \\
\hline & No & 220 & $3.08 \pm 0.85$ & \\
\hline \multirow{2}{*}{$\begin{array}{l}\text { Items about smoking (ex. smoker/nonsmoker, length of smoking, plans to } \\
\text { quit) }\end{array}$} & Yes & 200 & $4.12 \pm 0.74$ & $<0.001$ \\
\hline & No & 103 & $3.29 \pm 0.83$ & \\
\hline \multirow{2}{*}{$\begin{array}{l}\text { Items about drinking alcohol (ex. alcohol user/non-user, amount of } \\
\text { drinking, length of drinking, plans to quit) }\end{array}$} & Yes & 144 & $3.96 \pm 0.81$ & $<0.001$ \\
\hline & No & 159 & $3.07 \pm 0.86$ & \\
\hline \multirow{2}{*}{$\begin{array}{l}\text { Items about oral health management (ex. toothbrushing technique, use of } \\
\text { oral hygiene products) }\end{array}$} & Yes & 178 & $4.25 \pm 0.77$ & $<0.001$ \\
\hline & No & 125 & $3.20 \pm 0.92$ & \\
\hline \multirow{2}{*}{$\begin{array}{l}\text { Items about pre-treatment requests (ex. want overall treatment, want } \\
\text { treatment for only urgent problems) }\end{array}$} & Yes & 272 & $4.42 \pm 0.73$ & $<0.001$ \\
\hline & No & 31 & $3.32 \pm 0.87$ & \\
\hline
\end{tabular}

p-value by t-test.

The participants perceived items about oral health behaviors, patient's requests before treatment, and scaling to be the most important but items about cariogenic food consumption and drinking to be less important.

\section{Reason for noncompliance with detailed history taking}

The reasons for noncompliance with detailed history taking were already used a questionnaire by the facility $(39.6 \%)$, lack of time (38.3\%), staff shortage $(17.8 \%)$, and other $(15.5 \%)$ (Table 7$)$. Only 3 of the participants checked the reason that they just did not feel like it (1.0\%). 
Table 7. Reason for Noncompliance with Detailed History Taking

\begin{tabular}{lcc}
\hline \multicolumn{1}{c}{ Variable } & Frequency & $\%$ \\
\hline Lack of time & 116 & 38.3 \\
There is already a questionnaire used & 120 & 39.6 \\
by the facility & & \\
Just don't feel like it & 3 & 1.0 \\
Staff shortage & 54 & 17.8 \\
Other & 47 & 15.5 \\
\hline
\end{tabular}

\section{Discussion}

This study aimed to investigate the current status of initial history taking and contents of history taking in dental hospitals and clinics, ultimately to broaden the awareness of correct history taking and management and provide foundational data for developing a detailed and standardized questionnaire for dental history taking.

The results showed that compliance with history taking about dental history and oral health behaviors was higher among participants with a career of less than five years, while lower among participants with a career of 10 15 years. Due to the lack of comparable study findings, further studies are needed to substantiate these results, and various refresher educations and seminars should be provided for more experienced dental hygienists to instill the importance of initial history taking as middle managers.

Furthermore, most hospitals and clinics used both verbal and written questionnaires for history taking (94.4\%), and $\mathrm{Heo}^{9)}$ reported that history taking is performed only when necessary. While the present study surveyed the status of overall initial taking history, the said study examined the status of history taking for osteoporosis patients and management before and after dental care, calling for further studies with a larger sample and broader regions.

Regarding the perceived importance according to compliance with specific categories of the systemic disease history section, all items were significant with the exception of items about medications. South Korea is at the brink of becoming a super-aged society ${ }^{10)}$, and $88.5 \%$ of older adults aged 65 years or older are suffering from a chronic disease ${ }^{11)}$; the number of medications taken by individuals is increasing, and interests on geriatric diseases are mounting. Thus, understanding patients' currently used medications and disease history is crucial to preventing potential medical malpractices ${ }^{12}$. Therefore, dental hygienists should gain broader understanding of diseases and medications of their elderly patients to provide an appropriate intervention and recognize the importance of initial history taking.

In terms of compliance with specific categories in the systemic disease section, compliance rate was the highest for diabetes mellitus and hypertension at $96.7 \%$ each and lowest for sexually transmitted diseases and mental disorders. Han et al. ${ }^{13)}$ reported that HIV, herpes, and syphilis factors are transmitted via blood or saliva. Dental hospitals and clinics feature a high risk for infection from exposure to infectious microorganisms and aerosol and particularly a high risk for opportunistic infections through patients ${ }^{12}$. To prevent such infection risks, crosscontamination between dental care providers and patients should be prevented as a measure for primary prevention by taking history from patients.

Further, Lee and $\mathrm{Kim}^{14)}$ observed that the mentally ill have poorer oral health compared to the general population. This shows that mental disorders predict oral health status, and so mental disorders should be identified during history taking.

Regarding dental history, compliance and perceived importance were the highest for current oral symptoms. This may be due to the fact that oral symptoms are the ultimate reason for patients' dental visit and that they are most strongly associated with dental expenditure and oral health management. One critical competency demanded of dental hygienists for this is communication. Thus, dental hygienists should be able to engage in effective communication during history taking to adequately obtain information about patient's oral status and identify any discomforts so as to help subsequent care and treatment ${ }^{14)}$. Perceived importance and compliance were the lowest for radiotherapy in the head and neck region. Head and neck radiotherapy may induce acute or long-term adverse oral complications. Among various adverse reactions, one common one is the damage to the salivary glands, and this has been reported to affect both oral health, such as causing dry mouth, burning mouth syndrome, and acute dental caries, as well as systemic health. Therefore, identifying history of head and neck radiotherapy could be 
conducive to identifying the causes of oral symptoms, and thus compliance with history taking of this area should be improved.

Regarding oral health behaviors, compliance and perceived importance were high for items about requests before treatment and scaling. To survey patients' requests before treatment, it is important to identify their needs. The first step in motivation is to immediately identify the needs of the patient, and immediately addressing the patient's needs help acquire patient's trust and faith. Such trust helps to advance to the next step ${ }^{15)}$, which may be the reason underlying the high compliance rate and perceived importance. Further, Jung et al. ${ }^{16)}$ reported that scaling not only prevents and treats gingival diseases early but also is significant as a step preceding periodontal treatment. Therefore, compliance and perceived importance for taking history of scaling seem to be high, as it can help with the treatment and prevention of oral diseases.

On the other hand, both compliance and perceived importance were low for items about cariogenic foods. According to Honkala et al. ${ }^{17)}$, the frequency of sweet food intake is associated with the number of carious teeth. It would be imperative that dental hygienists identify cariogenic foods that patients consume and provide dietary guidance in addition to providing assistance in dental care in order to induce changes in oral health behaviors.

Finally, the most common reason for noncompliance despite perceiving the importance of using detailed items for initial history taking was having a hospital-developed questionnaire or not having enough time. Thus, the method and items used for history taking should be standardized across dental hospitals, and a brief and practical questionnaire should be developed such that it can be utilized in the hectic schedules in dental hospitals and clinics. Further, education programs should be provided for dental staff such that they can recognize the importance of initial dental history taking and contribute to actively complying to it.

Some limitations of this study are that the sample was confined to a single region in the Gyeonggi province, which limits the generalizability of the findings. Further, only a self-report questionnaire was used, so the accuracy of the responses may vary depending on the participant's comprehension of the items. In addition, currently, studies on dental history taking are lacking, necessitating expanding the region and scope of sample nationwide, along with the use of various methodologies, including questionnaires and interviews.

Despite these limitations, this study is the first study on dental history taking and provides foundational data for developing more detailed and standardized questionnaire in the future.

\section{Notes}

\section{Conflict of interest}

No potential conflict of interest relevant to this article was reported.

\section{Ethical approval}

This study was approved by the Institutional Review Board of Eulji University (IRB-2019-5).

\section{Author contributions}

Conceptualization: Hee-Jung Lim and Do-Seon Lim. Data acquisition: Do-Seon Lim, Im-Hee Jung, Ae-Jung Im, and Hee-Jung Lim. Formal analysis: Do-Seon Lim, Im-Hee Jung, Ae-Jung Im, and Hee-Jung Lim. Funding: none. Supervision: Hee-Jung Lim. Writing-original draft: Do-Seon Lim, Im-Hee Jung, Ae-Jung Im, and Hee-Jung Lim. Writing - review \& editing: Do-Seon Lim, Im-Hee Jung, Ae-Jung Im, and Hee-Jung Lim.

\section{ORCID}

Do-Seon Lim, https://orcid.org/0000-0003-4602-3323

Im-Hee Jung, https://orcid.org/0000-0002-8645-1587

Ae-Jung Im, https://orcid.org/0000-0003-2752-7112

Hee-Jung Lim, https://orcid.org/0000-0002-4738-3032

\section{Reference}

1. Statistics Korea: Population and housing census report 2017. Retrieved May 19, 2020, from https://www.kostat.go.kr/ portal/korea/kor_nw/3/index.board?bmode $=$ read\&aSeq $=370$ 298(2018, August 27).

2. Korea Centers for Disease Control and Prevention: Korea 
health statistics 2017: Korea National Health and Nutrition Examination Survey (KNHANES VII-2). Retrieved May 19, 2020, from https://knhanes.cdc.go.kr/knhanes/sub04/sub04_ 03.do? classType $=7$ (2019, January 11).

3. Ministry of Health and Welfare: 2017 National survey of older Koreans frailty. Retrieved May 19, 2020, from http:// www.mohw.go.kr/react/jb/sjb030301vw.jsp?PAR_MENU_I $\mathrm{D}=03 \&$ MENU_ID $=032901 \&$ CONT_SEQ $=344953$ \&page $=1$ (2018, May 30).

4. Park TS: Review of the Japanese cases on the duty of medical inquiry. Korean J Med Law 8: 63-82, 2000.

5. Korea Medical Dispute Mediation and Arbitration Agency: [Dental-Implant] Cerebral infarction after tooth extraction and implant placement. Retrieved May 19, 2020, from https:// www.k-medi.or.kr/lay1/bbs/S1T118C124/A/89/view.do?arti cle_seq=3783(2018, October 19).

6. Marx RE: Pamidronate (Aredia) and zoledronate (Zometa) induced avascular necrosis of the jaws: a growing epidemic. $\mathrm{J}$ Oral Maxillofac Surg 61: 1115-1117, 2003. https://doi.org/10.1016/s0278-2391(03)00720-1

7. Baek JY, Jeon HS, Lee JH: Management of osteoporosis patients for prosthetic restoration. J Dent Rehabil Appl Sci 32: 93-101, 2016. https://doi.org/10.14368/jdras.2016.32.2.93

8. Park MS, Kim HJ, Bae SM, et al.: Introduction to dental hygiene. 3rd ed. DaehanNarae Publishing, Seoul, pp.6-10, 2020.

9. Heo JM: Status of dental medical questionnaire for BRONJ prevention. Unpublished master's thesis, Inje University, Inje, 2016.
10. Statistics Korea: Population status and prospects of the world and Korea reflecting the special estimate of future population in 2019. Retrieved December 2, 2020, from http://kostat. go.kr/portal/korea/kor_nw/1/1/index.board?bmode=read\&bS eq $=\&$ aSeq $=377226 \&$ page $\mathrm{No}=1 \&$ rowNum $=10 \&$ navCount $=1$ $0 \&$ currPg $=\&$ searchInfo $=\&$ sTarget $=$ title $\&$ s Txt $=(2019$, September 2).

11. Lim GT: Factors affecting suicidal ideation by medical institutions users- focusing on elderly people with chronic diseases. J Korea Contents Assoc 19: 644-654, 2019. https://doi.org/10.5392/JKCA.2019.19.06.644

12. Kwon JL, Kim KE, Kim SK, et al.: Infection control. Well, Seoul, pp.12-15, 2016.

13. Han SJ, Lee JH, Kim KW: The effectiveness of decontamination methods in dental instruments. J Korean Assoc Maxillofac Plast Reconstr Surg 24: 196-201, 2002.

14. Lee JY, Kim CH: A study of oral health status in handicapped students comparing with normal students. J Dent Hyg Sci 2: 115-119, 2002.

15. Chang KW, Hwang YS, Ku IY, et al.: Oral health education. 4th ed. Komoonsa, Seoul, pp.82-84, 2017.

16. Jung EK, Nam YO, Jin $\mathrm{SH}$, Seo ND, Kim JS, Nam CH: Scaling behavior of manufacturing industry worker. Korean J Health Educ Promot 22: 1-16, 2005.

17. Honkala E, Nyyssönen V, Kolmakow S, Lammi S: Factors predicting caries risk in children. Scand J Dent Res 92: 134-140, 1984.

https://doi.org/10.1111/j.1600-0722.1984.tb00869.x 